\title{
The Artistic Expression in Contemporary China
}

\author{
Wanshi Ma \\ Art History, College of Art and Science, New York University, 10012 \\ wm738@nyu.edu
}

Keywords: Song Dong, contemporary China, Cultural Revolution, performing artist

\begin{abstract}
Song Dong is one of the leading contemporary artists in China. His conceptual pieces invite us into his personal experience of culture and family along with the country's rapid development, while resonating with us through a connection to collective history. Born in the winter of 1966 in Beijing, Song grew up and lived in a dazayuan, a large courtyard that is populated by a large family. The multigenerational environment fostered a pleasant engagement between Song and his family members. His love and affection for his family later became an essential component of art creations. Song graduated from Capital Normal University in Beijing studying oil painting, but abandoned his academic training due to the impact from the June Fourth movement and the introduction of new contemporary art forms to China. As the framed canvas came to feel limiting for his artistic creation, he discovered freedom in works ranging from performance to installation. He integrates the realities of everyday experience into art productions, with the idea that personal stories and ordinary objects could suggest the effects of social and political changes. Touching My Father uncovers the story of his father; Waste Not revives the memories of his mother; Wisdom of the Poor reveals his growing up environment. The works he has created frequently relate to the theme of his relationship with his family members and their experience of living in modern China. "I always want to make my family members the subject of my art. An artist who is concerned with life naturally wants to investigate into reality deeply; no reality is closer to me than my family,” said Song Dong during an interview. His quotidian emotions, especially his love and transmission of that love, turned into powerful artworks that distinguished him from many contemporary Chinese artists who were also dealing with the rapid change that China underwent [1].
\end{abstract}

\section{Introduction}

Song's life started during the beginning of Cultural Revolution (1966-1967). Until he was twelve Song Dong hardly knew his father, who was denounced as counter-revolutionary and returned home only occasionally from the camps. Song's impression of his father was a combination of veneration and fear. "Father guides son" is an ethical code derived from the Confucian household, which continues to guide the everyday lives of Chinese people, stipulating the position of father as ruler of the family. Song grew up in an environment that centered around this value. In 1977 Song went to Berlin and became homesick in the new environment. Thinking of their relationship, Song wanted to show his love and to feel a close connection to his father, which is impossible because of the estrangement between them. Finally, Song came up with the idea of achieving this through art, and he called this work Touching My Father. Over the period from 1997 to 2011, Song presented the Touching My Father Trio. For the first part of the series, he videotaped his hand touching the air in the dark, and projected the dazzling image of his hand onto his father's body, creating the effect of touching his father but without physical contact. Starting from his father's face, Song's hand swept across the body slowly, and eventually stopped at his father's heart.

When I was touching my father with my projected hand, he was smoking. Unexpectedly, with his eyes on my "hand", he started to take off his jacket, shirt, and vest until he was half naked, feeling my hand on his bare back...

The intimate yet indirect contact between the virtual hand and the physical body generated a complex feeling toward both Song and his father, who did feel the touch. This projection avoids the 
disrespectfulness of directly touching one's father, and expresses a complicated emotion that many Chinese have toward their fathers, love bounded up by fear. Art bridged the invisible gap and connected Song with his father. The artwork opened up new possibilities of communication between father and son, but at the same time, Song still respected the authority and dignity of his father. Both father and son still maintained individuality. Song is truly grateful for art, which gradually started to enter his family life and become the center of their lives, creating a closer bond between family members.

The work Touching My Father was a breakthrough in Song Dong's relationship with his father, and it also created new tensions which motivated them to make continuous efforts to improve their relationship. One problem was "the unequal positions of the two men involved: the father was passive and immobile. In fact, although he participated in this project, he was objectified and could neither see nor feel his son touching him”. Moreover, his father considered this experiment to be a strictly private matter, but to Song Dong this art project requires the participation of audience [2]. A transformation in modes of thinking between different generations was evident, yet this generation gap was difficult to evade.

In 2002, cardiac failure took Song's father's life suddenly, a traumatic moment for Song. It was not until his father passed away that he truly understood the meaning of lament. He was finally brave enough to touch his father with his real hands, but by that time, his father's body was cold, much like his own heart. Song recorded on video his hand touching the cold body of his father's corpse, but even today he is incapable of watching it. He sealed up the only tape so that it will not be viewed. The video remains invisible and intangible, but it is embedded and always presents in Song's mind and soul. There has always been a voice inside Song that pushed him to think about his father, to touch his father since his father's death, but it took him eight years to be able to face his father's image. In the third version of Touching My Father, through projecting his father's image onto water, Song touched the watery face with his hand. This time, the touching was difficult. When his hand reached the water's surface, the image vanished, and when his hand lifted up, the image reappeared. When he could no longer stay by his father's side, art helped him create a contact with his father.

Song Dong is trying to touch the material presence of his father. In the first stage of this project, his father was not there. Song was imagining touching his father, but he was just touching the air. In the second stage, he was really touching the physical presence of his father, but he was not able to in that his father was gone. According to Wu Hung, "the whole project is a wonderful metaphorical representation of desire and the impossibility of fully realizing desire. Activated by imagination, Song Dong's moving hand in the first stage of the experiment represented his desire in its purest form as his longing to touch his father. In the second phase of the experiment, he tried to materialize this longing, but the attempt was compromised when a representation replaced his real hand". In both situations, he was not quite touching his father, touching and not touching at the same time. The third expression is combination of the previous instance. It shows how illusive materiality is. The medium of water illustrates the difficulty of the touch. There is the physical presence of the image, but it is impossible to touch the image in water, just as it is impossible to physically touch a father that was gone [3].

Touching My Father is a powerful statement of family love and the moral of filial piety in traditional Chinese culture. Through modern artistic techniques, Song Dong invites us into the concept of familial love in his culture, his family, and his heart. In modern society, under the influence of globalization and commercialization, change and obliteration of the past has become a general phenomenon. Familial love disappears rapidly, but for Song it never fades from view. "Regardless of in Song Dong's art or in his everyday life, his love for his parents, his wife and his daughter, and other family members is the same: His life is his art, and his art is also his life". Images and narratives created in the theme of family life reveal the inner self of this sensitive artist, while providing further insight into Song and his family. Traditional cultures and morals appear as constant theme so that we can still catch a glimpse of it.

The sudden death of Song Dong's father meant an irreversible loss for the whole family. Especially for his mother, Zhao Xiangyuan, it was immense pain. She went through a period of 
depression, during which she occupied her entire room with things that she had kept over the years to avoid seeing the room empty. "It was as if she were using these objects to build a cocoon for herself, finding warmth in it and the reasons for her survival."She filled the space with remnants from the past as a way to hold on to the old times shared by the family. Through extending the life of the objects, the memories attached on those continue. Unwilling to see his mother buried herself with the salvaged objects, Song tried every way to life his mother out of grief, and he turned to art as the final hope. Through exhibiting her life and her possessions, Song could free his mother from her "pathological attachment" to the past. In 2002, same year of his father's death, Song initiated an enormous installation as a place for his mother to put her memories and histories in order. Song asked his mother to help him with this art creation. They spent three years sorting out and categorizing numerous pieces of things that she refused to throw away yet which were seemingly useless. Over ten thousand possessions of Zhao were then assembled into the gallery space and were made into the art exhibition Waste Not, a collaborative work between mother and son [4]. Even though Zhao never considered herself an artist, all materials in the installation were collected and treasured by her. Common in every Chinese household in the 60s and 70s, used or partially used objects such as shoes, bottles, buttons, soap, utensils and furniture were transported to the ground of the exhibition space, unpacking the bygone era of that generation.

"Chinese people have a saying that it is the feelings imbued in the objects of one's life and home that gives them value, rather than the merely some objective quality". Imbued in the objects are the memories of Zhao's life, including her love and responsibility to her child. When life was difficult, she worried about the necessities of her children and therefore saved things for them. For example, the pile of laundry soap on displayed was something she saved for Song Dong. Soap had been a restricted commodity at that time, so she kept saving it during her lifetime. However, situations changed when people started to use washing machines, and the bars of soap that she has valued so much became useless. The era became ultimately different from her experience in the past. Song Dong, through this exhibition, was seeking for an impetus that could bring back to life Zhao's "body, psyche, and consciousness", which seems meaningless after the unexpected bereavement. He utilized material from everyday realities to revive the state of existence of his mother, and express his love with his parents [5].

Even though the functional value of the objects on display is lost, they still carry sentimental value, which made it impossible for Zhao to throw them away. "Regardless of the reason an object was kept, it would eventually become a 'site of memory'-its value as bearer of memory would eventually outlive its use value”. Zhang preserve them not only for the virtue of frugality, but also their underlying emotional quality. Each little piece was precious in that it vividly conveyed particular moments in her life, connecting the present with the past. These objects, modest and ordinary in life, acquire the materiality of Zhao's life narrative by documenting their association with her. "Each piece is connected to a particular moment in her life, and in turn associated with a person or persons with whom she had an intimate relationship”. The memory and history, Zhao's thrifty lifestyle and love for her family, turned into physical forms and existed in the actual objects that were displayed in the exhibition.

The act of saving everything for its potential usefulness is a common phenomenon in Chinese household. Song's mother called it "waste not", a traditional Chinese thrifty ethos towards life. At the times of a paucity of goods, frugality was the only way for a family to sustain. Due to the fear of shortage, Zhao kept collecting everything that could be kept, and the "waste not" spirit turned into her lifestyle, even at the times when goods were abundant. This philosophy of life is shared by the generation of people living around the same period, during which the situation faced by each family was identical. The frugal approach toward life was then transmitted from generation to generation and emerged as the dominant way of living for Chinese people. In the fast-paced environment under the context of globalization and commercialization, Song's exhibition is in a sense evoking traditional values, consolidating the virtuous idea that should continue to guide people. The concentration of Song's exhibition, which is on local culture and life of his family members, sets itself apart from the rapid globalization and commercialization trend that contemporary Chinese art is experiencing. 
Despite being the owner of the objects, Zhao also took an active role in transporting her private possessions into public display. Through transforming his mother's role into an artist, and giving her the job of organizing her things, Song's goal was to extract his mother from sorrow and bring happiness back to her life. During the exhibition, Song set up a corner for his mother so that people could come and talk to her. Therefore, Waste Not involves improvisation that is the direct contact between artist and audience. During the exhibition, Zhao would communicate with different audience, sharing her stories and life experiences with strangers. "The project would acquire a special performance dimension, with Xiangyuan serving as the performance artist”. To perform in Waste Not is to reminisce about what she remembered. She knew in detail the past and present of every object she had saved. In that sense, "her new gallery visitors, no less than her cumulatively saved old objects, functioned as memory triggers for her narrative projectiles". This interaction introduced vitality into Waste Not. Static objects were enlivened by the memories attached to them. Triggered by this old woman's voice, the Chinese tradition inherited in her belongings became legible and was transmitted to audiences. Consequently, her private possessions received public attention in the exhibition space. In this process, the mundane objects of Zhao's life acquired artistic values.

Zhao, as the performing artist, was the most visible person during the exhibition. Not only did she prepare and recreate her collections into installation in a public display, but also she maintained a close relationship with her objects, relating her stories to them. The collaboration between Song and Zhao transcended their former mother and son relationship to a partnership in artistic experiment. Just like it previously contributed for his relationship with his father, art once again helped strengthen the emotional tie between Song and his family members. Moreover, their collaboration "connected art making with a deeply rooted ethical tradition in Chinese culture centered on family relationship". Personal reflection of culture and family once again appeared as a pivotal theme of Song Dong's work. Accordingly, through transforming familial love to public sphere, the previously private matter stirred up communal affection and generated communication between strangers. In Beijing as well as in other places, "the exhibition evoked strong responses from the audience, some of whom wept in front of it as if encountering a long lost friend or relative. Other visitors characterized the installation as a new kind of cultural institution, preserving vestiges of ordinary lives and experiences that had eluded existing types of historical museums”. The exhibition opened up a space for different people to find commonalities in their own memory. Ordinary life entered into contemporary art world as a powerful statement that "reached a multitude of strangers and touch their hearts".

On the gallery's clerestory, illuminated blue Chinese characters made of neon lights were displayed in reverse and attached to the outside of the clerestory window. The characters, facing skywards, were meant to be viewed from outside. The sentence reads: 'Dad, don't worry, mum and we are fine!' The sentence is an indispensable component of the exhibition. It was designed not for the visitors, but exclusively for Song's father, who rested in heaven. The words realized a closer bond, consoling both his mother and his father as well. It seems as if the whole family was present, reuniting through the artwork. Therefore, the work itself is an emblem of familial love and filial piety.

After the exhibition Waste Not, a frequent question emerges regarding the size of Song's home. A lot of audiences assumed that he must have a large living space which is able to contain all those possessions. However, this is not the case. In his later exhibition, Wisdom of the Poor, Song gave an answer to this question by demonstrating ways that the poor used to utilize their limited space, achieving more space and right through their ingenuity. In the time of poverty and suffering, ordinary people coped with the hardship through thrift and hard work. They also used their intelligence and creativity to improve their living conditions. Living with the Tree, one of the works from the series, mimics the growing environment of Song in a conceptual way. A tree breaks through the center of a bed, which is placed in a room enclosed by old doors. The doors are metaphor of an alternation between private and public spheres. When doors are closed, the room is a private space; when doors are open, it is a public space that allows access. In his memory, dwellers of the dazayuan in Beijing constantly dealt with shift from public to private space. Occupying public area and turning it into private space is a way to extend their living space. Nevertheless, they could not expand their space when there was a tree, because it was against the regulation of tree protection. Therefore, when Song 
was young, many courtyards in Beijing were built with a tree in the center. By incorporating the tree into their home, people could use the space of the tree and therefore expanding their own living space. Through Living with the Tree, Song explicate the concept of "borrowing the surrounding scenery", which was a wisdom developed by the poor that enabled them to effectively apply space and improve their lives. For Song, the wisdom and spirit of the poor is worthy of respect even at the time when material wealth has increased. As his mother often said, "we are poor people. No matter how wealthy we become, poverty will always run in our veins". Even though the society has undergone radical transformation, the dazayuan was destructed for the construction of new residential buildings, the value of simple living and hard work still exists firmly in Song's heart and soul,

Song Dong's works, Touching My Father, Waste Not, and Wisdom of the Poor are all deep-rooted in his love for family and local culture. Being grateful to the generation who has nurtured him and his generation, Song through his artworks manifests the spiritual wealth and virtues inherited from them. He allows us to see how an artist living in a fast-paced environment could use his distinguished artistic expression and awareness of his own life to reiterate traditional values, which seems to vanish due to the influx of new knowledge and information. In the confrontation with globalization and commercialization, his deeply personal artistic language retains a spiritual connection to the legacy of his ancestors and local culture. Song quietly reveals the rapid development and societal change in modern China. He expresses the effects of social turbulence on his family members, while focusing on the transition of his love towards them. The love and affection that Song has towards his family emerges as the evidence of the political impact on the daily life of Chinese people. Globalization allows the dispersion of new ideas and the communication between different cultures. However, globalization is not the unification of diverse cultural forms, but it is a movement that promotes multiplicity. Song Dong, in both his life and art, resists to blindly follow the trend. Through his artworks, he is making a strong statement about his own existence in the modern world, with traditional Chinese philosophy and virtue constituting the primary part of his life.
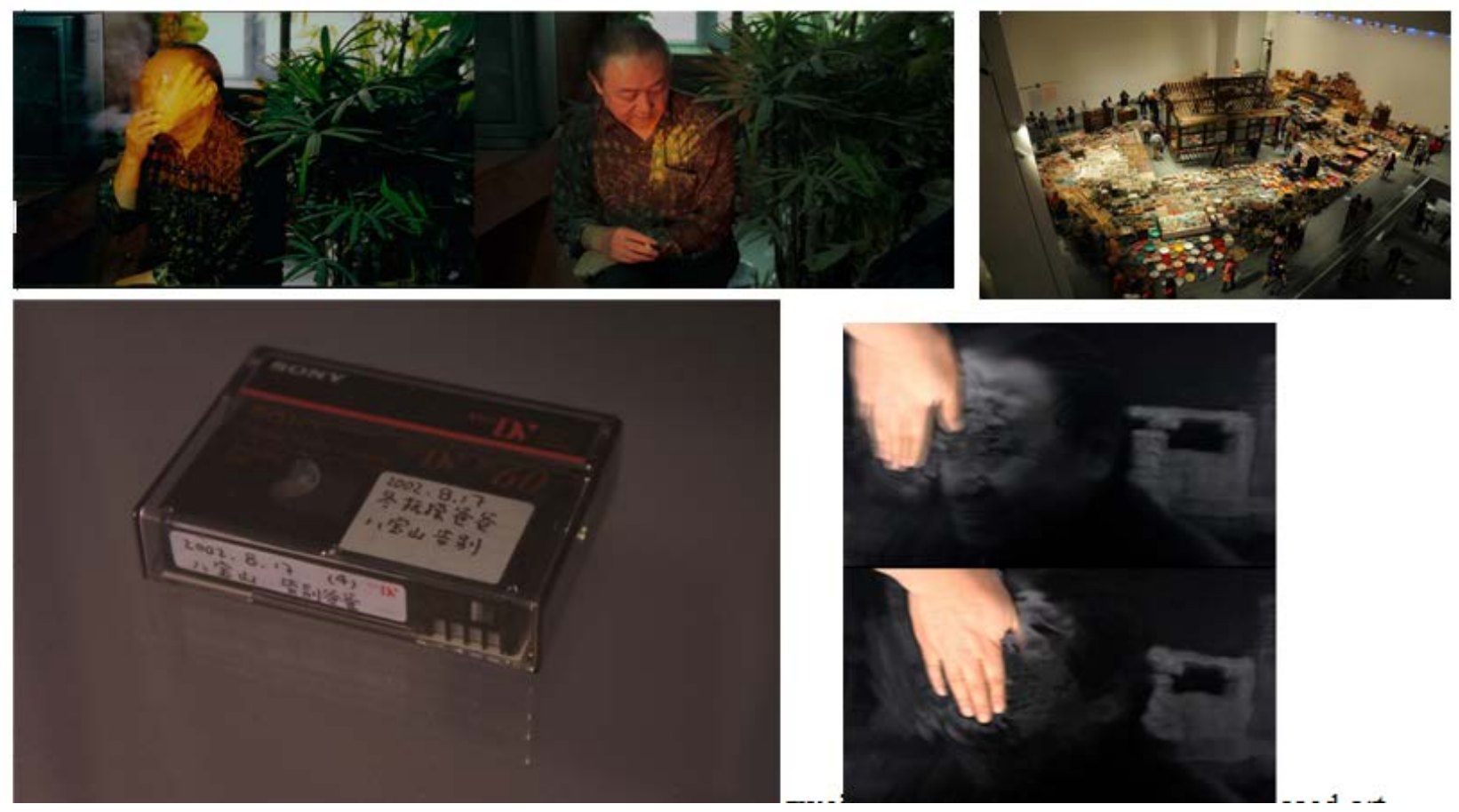

Fig.1 Touching My Father, Part 1, 1997.

\section{References}

[1]Cheng, Meiling, and Richard Schechner. Beijing Xingwei: contemporary Chinese time-based art. London: Seagull Books, 2013:21-22 
[2]Song, Dong. Song Dong: Dad and Mom, don't worry about us, we are all well. San Francisco: Yerba Buena Center for the Arts, 2011.

[3]Wang, Sabine. Song Dong. Ostfildern: Hatje Cantz Verlag, 2015:17-18

[4]Wu Hung. Remaking Beijing: Tiananmen Square and the creation of a political space. London: Reaktion, 2005:22-23

[5]Wu Hung. Exhibiting experimental art in China. Chicago: David and Alfred Smart Museum of Art, the University of Chicago, 2000:19-20 